\title{
THE PEDAGOGICAL PRACTICE - DIMENSION OF THE TRAINING OF FUTURE TEACHERS
}

\author{
Luminița Mihaela DRĂGHICESCU ${ }^{(1)}$, Ioana STĂNCESCU ${ }^{(2)}$, \\ Ana Maria Aurelia PETRESCU ${ }^{(3)}$, Gabriel GORGHIU ${ }^{(4)}$ \\ 1,2, 3,4 Teacher Training Department, Valahia University of Târgoviște \\ ROMANIA
}

E-mail: ${ }^{1}$ lumidraghicescu@yahoo.com, ${ }^{2}$ stancescu_ioana@yahoo.com, 3 anapetrescu2007@yahoo.com, ${ }^{4}$ ggorghiu@gmail.com

\begin{abstract}
The Romanian education system needs today, more than ever, good teachers, dedicated, devoted to their mission and aware of the major responsibility they must take on - accompanying the child on the path of his / her development, as a harmonious personality, and, thus, implicitly, to contribute to the "healing" of the society, which is marked by the dissolution of real values. In this context, the universities - especially through the teacher training departments -, have to be engaged in an efficient approach, oriented towards the formation of the professional competences related to the teaching career. The realization of such approach implies the prioritization of the pedagogical practical activities, in which the collaboration between all the factors involved in this process is important: students, mentors, coordinators of practical activities and, last but not least, teachers of pedagogy, psychology and didacticians. The present study is focused on the analysis of the opinions of the practitioner-students and teacher-mentors regarding the organization and leading of pedagogical practical activities. The investigative approach was made through a questionnaire-based investigation. Its items are focused, in particular, on the collaboration between two main actors of the pedagogical practical activities: the student-practitioner and the teacher-mentor. The purpose of this investigation was to obtain relevant feedback and to identify concrete measures or ways for improving the pedagogical practical activities.
\end{abstract}

Keywords: didactic career; initial teacher's training; professional competences; transversal competences; pedagogical practical activities;

\section{INTRODUCTION}

In a society troubled by various changes that occur in all the fields of activity, the only institution responsible for preserving and disseminating authentic values remains the school. In this context, the main responsible actors are the teachers, who must become aware and assume their mission: to provide a quality education, not only for the actual generation of children, but a quality education for a whole nation, for maintaining its moral health and contributing to its revival.

The teaching profession therefore implies an immense social responsibility. In this respect, the initial training process for the teaching career must be permanently monitored 
and adjusted, in order to identify and integrate in a timely manner any experience of good practice that can generate the improvement of the expected results, which are materialized in solid professional and transversal competences of the people who want a teaching career.

"Teaching is a complex task, which requires a broad set of competences, the ability to apply them in varying situations, and the readiness and opportunity to develop them continuously. Initial teacher education offers candidate teachers knowledge and skills, which they can then practice and develop further in their professional life", shows the Report of the European Committee - Education and Training. Monitor 2019 (2019, p. 27).

One of the components of major importance in this process is represented by the pedagogical practical activities, when the practitioner-student can directly exercise, being monitored and advised by the mentor teacher, and ready to acquire necessary skills. If we analyze the picture of the defining competences for the teaching profession - didactic, psycho-educational, psycho-social, managerial and socio-educational -, we find that such activities, confined to the pedagogical practical activities, allow the formation / consolidation / development of the abovementioned competences.

The more necessary become the careful monitoring and prompt intervention in order to improve the pedagogical practice activities, the more "initial teacher education modules offer less preparation than programmes in other European countries, especially in practical domains" (2017, p. 123), as it is shown in an OECD Report - Reviews of Evaluation and Assessment in Education. Romania 2017.

If we refer to the curriculum related to the initial training process for the teaching profession, we consider, like all those who are concerned about increasing the quality of this process, that "teaching practice is (...) the most important part of pedagogical studies, which helps future teachers take a full part in the school life." (Rauduvaite, Lasauskiene, Barkauskaite, 2015, p. 1052).

\section{BEST PRACTICES RELATED TO PEDAGOGICAL PRACTICAL ACTIVITIES 1.1. Description of the best practice model}

In a study carried out in 2015, Martinjak apreciate that "a teacher's practical education and training are very important first steps in the real world development of a teacher's praxis" (2015, p. 192). With the same perception on the importance of the pedagogical practical activities in the process of initial training of the teaching staff, the Teacher Training Department from Valahia University of Târgoviște has been constantly involved in organizing, monitoring, evaluating and adjusting the activities subordinated to this demarche.

Thus, at the end of each semester, feed-back questionnaires are administered to the coordinating teachers of pedagogical practical activities, but also to the teacher-mentors from schools and students.

The questionnaires envisage to specific aspects of the pedagogical practical activities, mainly targeting on:

- the relationship established between the main actors of the pedagogical practical activities: (coordinating teacher) - (teacher-mentor) - (student-practitioner);

- the involvement of the coordinating teachers, the teacher-mentors and students in an efficient organization and development of the pedagogical practical activities;

- the identification of the dysfunctions that exist at the level of the various activities subsumed to the pedagogical practical activities; 
- the identification of specific ways / measures for optimizing the whole process.

The data collected by the mean of those tools are supplemented with the information recorded after the semiannual meetings, in the format of focus groups, with participants from each of the three categories mentioned above.

\subsection{Specific objectives}

Through the best practice model described above, the following objectives are addressed:

- analysis of the perception of the practitioner students / coordinating teachers / teachermentors, concerning the efficiency of the organizing and conducting pedagogical practical activities;

- identification of proper ways / measures for optimizing the pedagogical practical activities.

\subsection{Proposed activities in the best practice context}

In accordance with the specific requirements of an approach that aims to optimize the educational activities, it was necessary to carry out activities such as: delimiting the problem, formulating the objectives; establishing the specific strategy / methodology; elaborating the research tools (feed-back questionnaires); pre-testing research tools; reviewing of the questionnaire feed-back; conducting the survey based on questionnaire; organizing the focus groups; processing and interpretation of results; capitalizing the obtained results, and, respectively, evaluating the impact of best practice.

\subsection{Recorded results}

In order to demonstrate the effectiveness of this model of best practice - designed by the Teacher Training Department from Valahia University Târgoviște -, we present, synthetically, the data collected after the administration of questionnaires to students and mentor teachers, at the end of the first semester of the 2017-2018 academic year. The datawas statistically processed and interpreted, in correlation with that registered within the two focus groups organized with practitioner-students and mentor-teachers.

The target group consisted of 260 students and 27 mentor teachers.

The quantitative and qualitative analysis of the collected information generated several interpretations:

\subsubsection{Practitioner students' feed-back}

One of the items of the questionnaire dedicated to practitioner-students envisaged the extent to which they appreciate that the mentor-teachers provided them with a relevant feedback at the end of the pilot and final lessons. The percentage of respondents who appreciate that mentor-teachers provide them - to a very large extent and to a large extent - a relevant feed-back, at the end of the lessons, is $96 \%$ (fig. 1).

The positive students' feed-back related to mentor-teachers confirms the concern of the department training staff, along with its partners in such activities - Dâmbovița County Scholar Inspectorate and the schools, as units of application -for making a permanent selection of the teacher-mentors, based on clearly defined criteria. 
The existence of $4 \%$ of the respondents who consider that the feedback is only relevant to a small or moderate extent, can be explained by the subjectivity expressed by them, as a result of the low marks received in the support of the pilot and final lessons.

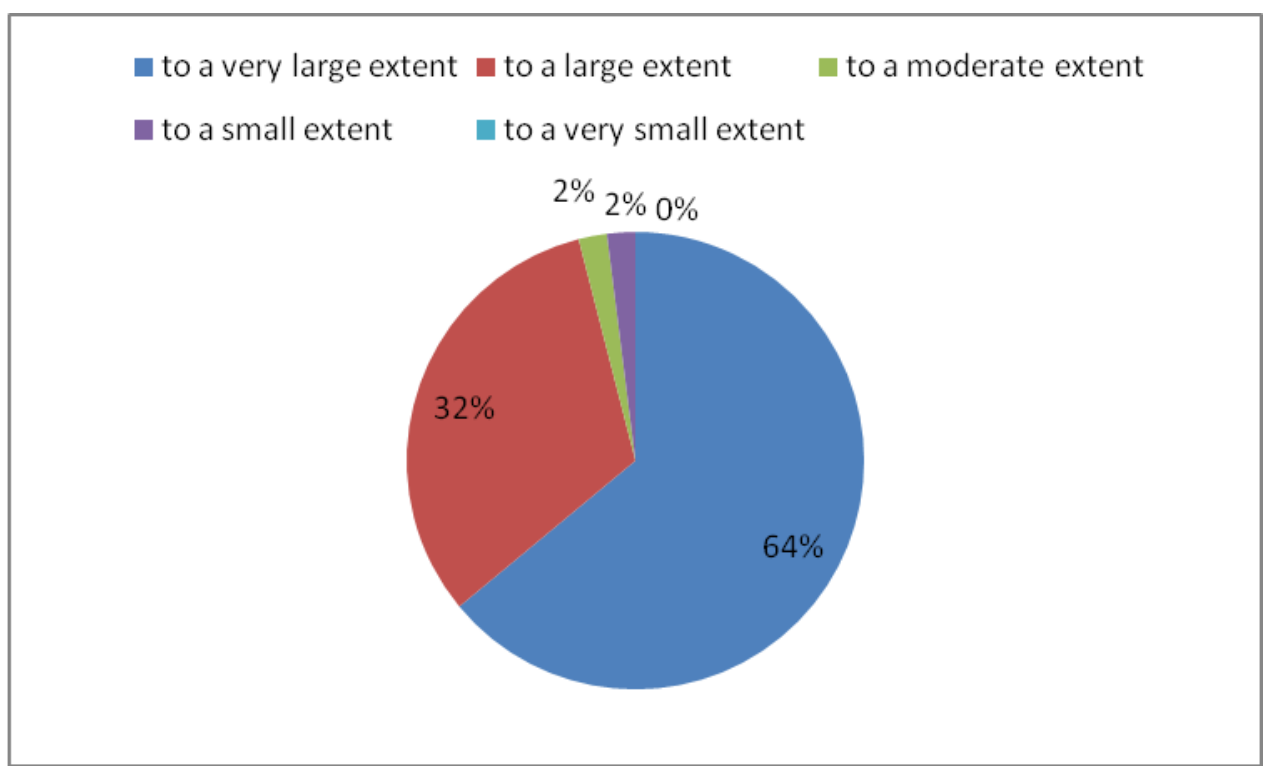

Figura1. Practitioner students' feed-back concerning the feed-back offered by the mentor-teachers

With the help of another item of the questionnaire administered to students, we targeted to identify the measure in which they consider that they benefited from the support of the mentor-teacher for identifying clear ways to optimize the didactic approach. Moreover, the improvement of the educational act must be a constant concern for each teacher, regardless of the accumulated teaching experience. Moreover, the practicing students, being for the first time in the situation on managing themselves of all the variables which are specific to an instructional context, they need support in order to raise the awareness of the strengths of the lesson, but also the problematic aspects, mostly those which can be optimized and, above all, how can be achieved.

Following the distribution of the data recorded on this item, we can notice again, that in a very high percentage, respectively $93 \%$, the respondents confirm the consistent support they receive from the teachers with a mentor status, in order to improve the subsequent training demarches. However, there are also practicing students (7\%) who appreciate that mentoring teachers offer them suggestions for optimizing future lessons, to a moderate extent (fig. 2). 


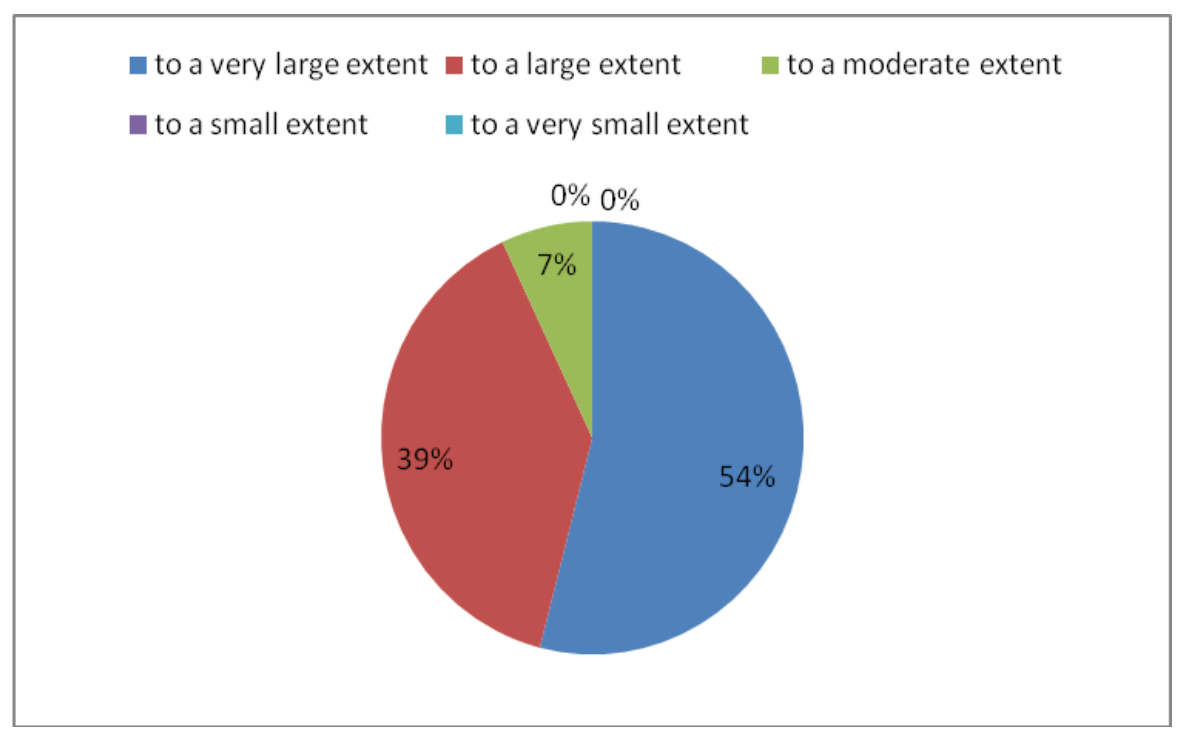

Figura 2. Practitioner students' feed-back concerning the support offered by the mentor-teachers in order to improve the didactic demarches

This is one of the issues we analyzed in the focus group organized with the mentorteachers, the last ones underlining on the following explanation: "Students do not have enough confidence in them, they do not use their own creative potential and often expect solutions only from the mentor-teachers."

Being asked about the extent to which they appreciate that the mentor-teacher, in the context of the analysis of the observed / sustained lessons, stimulates them to develop their assessment / self-assessment skills, the practitioner-students provided us with answers that led us to the following findings:

- the analysis of the lessons is carried out with responsibility and professionalism;

- the mentor-teachers stimulate students to get involved in the evaluation / self-assessment demarches, based on the criteria included in the lesson observation sheet (Drăghicescu et al., 2018, p. 34) and on the items from the reflection sheet (Drăghicescu et al., 2018, p. 42), thus contributing to the training / development of the specific skills of a reflective practitioner (fig. 3).

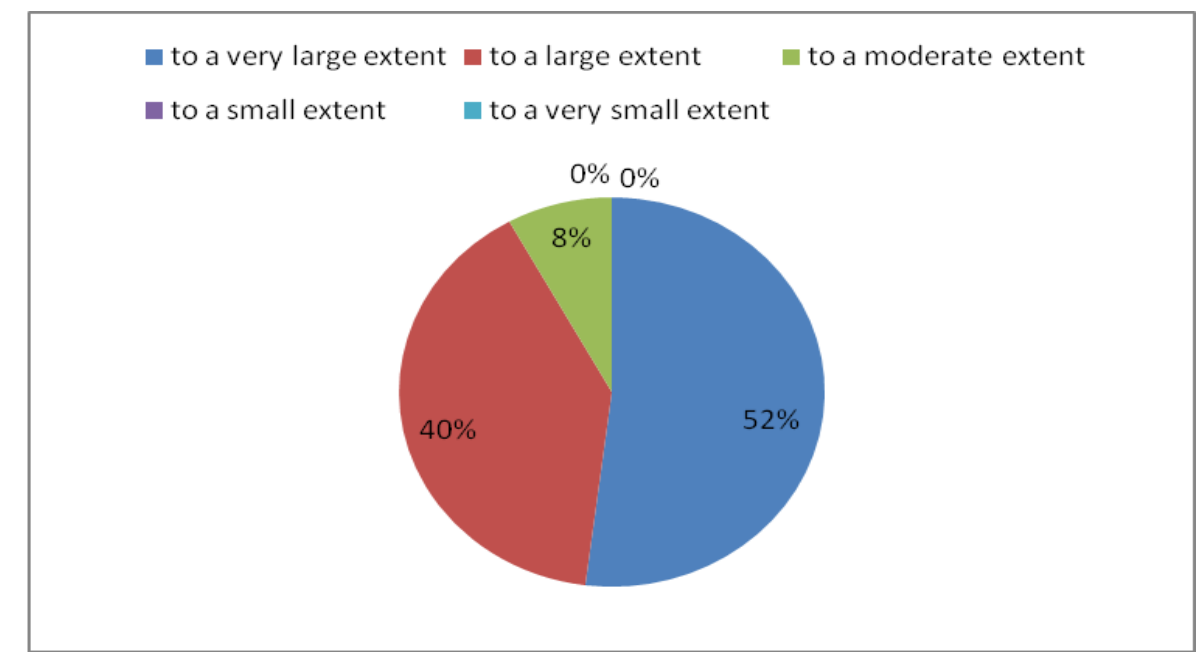

Figura 3. Practitioner students' feed-back concerning the measure in which they receive support offered by the mentor-teachers for developing the evaluation / self-assessment skills 


\subsubsection{Mentor-teachers' feed-back}

One of the questions included in the questionnaire administered to the mentor-teachers aimed to identify their perception regarding the involvement of the students participating in the pedagogical practical activities, when designing and implementing the didactic approaches.

According to the feed-back offered by $80 \%$ of them (fig. 4), the students are very involved in the actions concerning the effective designing and implementation of lessons, which demonstrates a responsible attitude, but also confirms that the choice to participate to the Initial Psycho-pedagogical Training Program was a good and assumed decision, doubled by the motivation to invest in the complex process of becoming a teacher.

We also note a percentage of $20 \%$ of the respondents who consider that the practicing students are largely involved in the activities specific to the pedagogical practical activities. According to the recorded data, we mention that those students come, in particular, from the faculties that do not have a didactic profile (Engineers, Law, Economics), their motivation to invest in such training for a teaching career being considerable lower.



Figura 4. Mentor-teachers' feed-back concerning the implication of practitioner students concerning the designing and implementing of didactic demarches

Regarding the appreciation of the mentor-teachers related to the students' participation with relevant observations - in the analysis / self-analysis of the lessons observed or implemented, and demonstrating real evaluation / self-evaluation abilities, a percentage of 93\% of them (fig. 5) stated that the students participate to this action to a very great extent and to a great extent, which confirms that they have a solid psycho-pedagogical and didactic preparation, and can relate objectively to their own educational approach, as well as to that of their colleagues. 


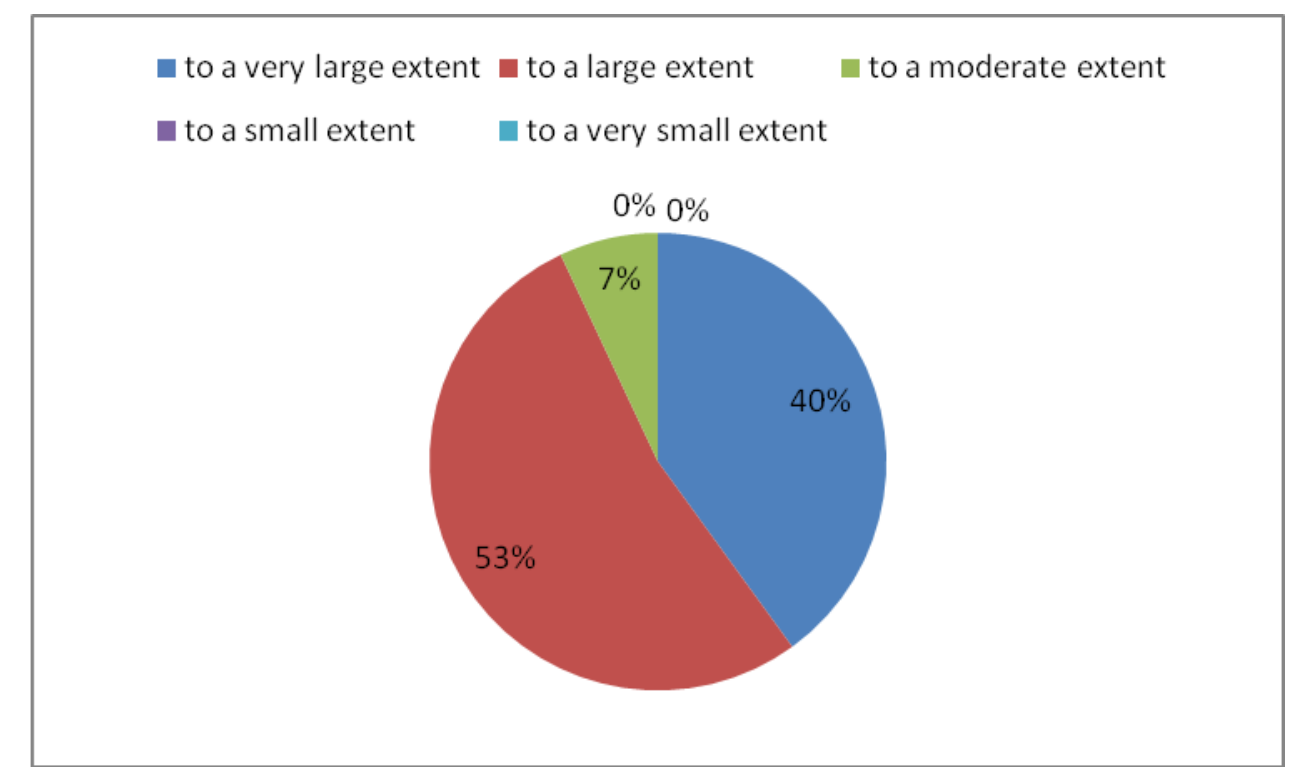

Figura 5. Mentor-teachers' feed-back concerning the participation of practitioner students to the analysis / self-analysis of the lessons

It can be noticed that in the training process of their assessment / self-assessment capabilities, useful tools proved to be the Lesson observation Sheet (Drăghicescu et al., 2018, p. 34) and the Reflection Sheet (Drăghicescu et al., 2018, p. 42), both subsuming their relevant criteria from this point of view.

The percentage of $7 \%$ of the respondents who consider that the students participate moderately in the analysis / self-analysis activities, is explained, to a certain extent, by the fact that the students to whom they refer, come in particular, from faculties that do not have a didactic profile.

Both categories of respondents were asked, by the mean of the administered questionnaire and within the organized focus groups, to identify or mention ways / measures / suggestions for optimizing the pedagogical practical activities. From the received answers, we selected the following ones, specifying that some of them have already been implemented:

- a better correlation between the pedagogical practical program and the mentorteacher's schedule;

- a greater number of hours allocated to pedagogical practical activities in general, and observational practice in particular;

- supporting several test/pilot lessons;

- using of several modern teaching methods and tools;

- fast notifying of the problems faced by the practitioner-student in the classroom / lesson management process;

- better collaboration between practicing students;

- timely identification of the needs of practicing students etc.

\section{CONCLUSION}


The main difficulties, problems or limits identified in the integration of thepedagogical practical activities within the specific framework were:

- a light resistance manifested by the coordinating teachers of pedagogical practical activities in the administration of the feed-back questionnaires and in the participation in the focus-group, probably generated by the interpretation of this approach as a control, respectively of excessive / unexpected monitoring of the activity carried out;

- for maintaining a status - as a coordinating teacher of pedagogical practical activities or as a mentor teacher - and demonstrating that they exercise their roles and fulfill their attributions specified in the documents that regulate such activities, the respondents had the tendency to "pimp" the reality, placing each other, in a favorable "light";

- the feed-back questionnaires also requested to mention the identity, which let the answers to be objectively affected;

- the collection of the administered questionnaires was also achieved overpassing the deadline, some of the coordinating teachers motivating the delay by expressing the desire to process, independently of the Teacher Training Department, the whole data (we specify that most of the coordinators of pedagogical practical activities come from faculties, not being members of the department).

In order to optimize the best practice, we identified the following measures or modalities, some of them being already applied:

- adequate training of the coordinating teachers of pedagogical practical activities, of the mentoring teachers and of the practitioner-students, regarding the purpose and the objectives aimed at implementing the pedagogical practical activities;

- anonymizing the feed-back questionnaires;

- developing the possibility to fill-in online feed-back questionnaires;

- involvement of coordinating teachers of pedagogical practical activities in the process of processing and interpreting the collected information.

We appreciate that the approach taken into account can be included in the category of best practice, because it has generated the following effects:

- more careful programming of the pedagogical practical activities, by establishing a correlation between the scheduling program of the coordinating teacher of pedagogical practical activities, of the mentor teacher and of the practicing students;

- planning and supporting several test/pilot lessons;

- use of several modern teaching methods and tools, both in demonstration lessons, as well as in the test/pilot and final lessons;

- a better collaboration between the main actors of the pedagogical practical activities, in order to optimize its subordinated activities;

- organizing the conditions for simulating lessons, mostly in the context of other studied disciplines (Student Class Management, Computer Assisted Instruction);

- raising the responsibility of all those involved in organizing and carrying out pedagogical practical activities;

- raising the crucial role played by the pedagogical practical activities in the initial training process for the teaching career. 
In conclusion, we consider that the pedagogical practical activities represents an essential dimension of the initial training for the teaching career, offering the appropriate framework for training / practicing / developing of all the professional and transversal competences, indispensable for a future profession in the big area of education, and ensuring the necessary conditions for the placement of the practitioner-student in different contexts, relevant in terms of the roles and duties specific to a teacher.

\section{REFRENCES}

[1] Drăghicescu, L. M., Petrescu, A. M., Stănescu, I., Santi, E. A., Gorghiu, G. 2018. Ghid de practică pedagogică. Document de uz intern. [Pedagogical practice guide. Internal use document]. Târgoviște: Universitatea Valahia.

[2] EUROPEAN COMMISSION. (2019). Education and Training Monitor 2019

https://ec.europa.eu/education/sites/education/files/document-library-docs/volume-1-2019-education-andtraining-monitor.pdf

[3] Kitchen, H., et al. (2017), Romania 2017, OECD Reviews of Evaluation and Assessment in Education, Paris: OECD Publishing. http://dx.doi.org/10.1787/9789264274051-en

[4] Martinjak, N.Z. (2015). Influence of Habitus and Practical Education on the Teachers' Pedagogical Praxis. Croatian Journal of Education, Vol. 17, Sp. Ed. No.2/2015, pp. 191-204. doi:10.15516/cje.v17i0.1530

[5] Rauduvaite, A., Lasauskiene, J., Barkauskaite, M. (2015). Experience in Teaching Practice of Pre-service Teachers: Analysis of Written Reflections. Procedia - Social and Behavioral Sciences, 191 (2015 ), pp. 1048 1053. doi: 10.1016/j.sbspro.2015.04.526 